УДК 547.913

\title{
КОМПОНЕНТНЫЙ СОСТАВ ЭФИРНОГО МАСЛА ПОЛЫНИ MЕTЕЛЬЧАТОЙ (ARTEMISIA SCOPARIA WALDST. ET KIT.), ПРОИЗРАСТАЮЩЕЙ В БУРЯТИИ И МОНГОЛИИ
}

() С.В. Жигжитюсапова ${ }^{1,2}$, Т.Э. Рандалова ${ }^{1 *}$, Л.Д. Раднаева ${ }^{1,2}$

'Бурятский государственный университет», ул. Смолина, 24а, Улан-Удэ, 670000 (Россия), e-mail: soktoevate@gmail.com

${ }^{2}$ Байкальский институт природопользования Сибирского отделения $P A H$, ул. Сахьяновой, 8, Улан-Удэ, 670047 (Россия)

Методом гидродистилляции выделено эфирное масло из надземной части полыни метельчатой (Artemisia scoparia Waldst. et Kit.), собранной в разных районах Республики Бурятии и Монголии. Выходы эфирного масла из надземной части A. scoparia, произрастающих в различных районах Бурятии и в Селенгинском аймаке Монголии, варьируют довольно в широких пределах от 0,06 до 0,40\%. Компонентный состав масла проанализирован методом хромато-масс-спектрометрии на газовом хроматографе Agilent Packard HP 6890 N с квадрупольным масс-спектрометром (HP MSD 5973) в качестве детектора. В общей сложности было обнаружено свыше 100 соединений. Основными компонентами масла полыни метельчатой были определены: $n$-цимол $(0,6-15,2 \%)$, лимонен $(0,1-6,3 \%)$, $\alpha$-пинен $(0,2-10,1 \%), \beta$-пинен $(0,4-8,9 \%)$, транс- $\beta$-оцимен $(0,3-5,4 \%)$, кариофиллен $(4,6-13,8 \%)$, гермакрен D (11,5$40,3 \%)$, спатуленол $(4,0-11,7 \%)$, оксид кариофиллена $(4,3-15,6 \%)$. По составу основных компонентов эфирные масла A. scoparia можно разделить на следующие хемотипы: 1) содержащие ацетиленовые углеводороды - из провинций Гилян, Мазандара, Кашан, Тигран Ирана, Таджикистана, а также европейской части СНГ; 2) содержащие монотерпеновые и ароматические соединения - из провинции Хорасан Иран, Индии, Южной Кореи; 3) содержащие монотерпеновые или ароматические и сесквитерпеновые соединения - Казахстан и Монголия. Основные компоненты эфирного масла A. scoparia флоры Бурятии представлены моно- и сесквитерпеновыми соединениями и соответствуют третьему хемотипу, характерному для полыни метельчатой из географически близких регионов.

Ключевые слова: эфирное масло, Artemisia scoparia Waldst.et Kit., газо-хромато-масс-спектрометрия.

\section{Введение}

Флора Бурятии и Монголии богата эфироносными растениями [1]. Полынь метельчатая Artemisia scoparia Waldst. Et Kit. (семейство Астровые Asteraceae) - травянистое растение, обычно произрастает на залежах, полях, по открытым склонам, межах [2]. В медицине народов Сибири надземную часть полыни метельчатой применяют при нарушениях менструального цикла и как желчегонное, улучшающее пищеварение, противоглистное средство. Растение в китайской, тибетской и индийской медицине используют в качестве антимикробного, мочегонного, жаропонижающего и противопростудного средства, при заболеваниях органов дыхания и как отхаркивающее. Эфирное масло, получаемое из этого вида полыни, входит в препарат артемизол, назначаемый в качестве спазмолитического, повышающего растворимость оксалат-

Жигжитапова Светлана Васильевна - доцент, старший научный сотрудник, кандидат биологических наук, тел.: (3012) 43-49-97, e-mail: Zhig2@ yandex.ru

Рандалова Туяна Эрдэмона - старший преподаватель, кандидат фармацевтических наук, тел.: (3012) 44-82-55, e-mail: soktoevate@gmail.com

Раднаева Лариса Доржиевна - заведующая кафедрой фармации, заведующая лабораторией химии природных систем, доктор химических наук, профессор, тел.: (3012) 43-49-97, e-mail: radld@mail.ru ных и известково-фосфатных солей в моче и способствующего выведению мочевых конкрементов средства [3]. Известно, что эфирное масло полыни метельчатой подавляет рост Escherichia coli, Candida albiconce, Cryptococcus neoformans [4].

Химический состав эфирного масла Artemisia scoparia описан для популяций

\footnotetext{
* Автор, с которым следует вести переписку.
} 
из различных стран, составы эфирного масла этого вида полыни из разных точек ареала заметно различаются [5-15].

Сведений же о химическом составе полыни метельчатой флоры Бурятии нет, поэтому исследование эфирного масла представляется актуальной задачей.

\section{Экспериментальная часть}

Сырье для получения эфирного масла собирали в ходе экспедиционных работ в период с 2008 по 2013 г. из разных популяций Бурятии и Монголии, в фазу цветения (табл. 1). Гербарные образцы хранятся в лаборатории химии природных систем, созданной на базе Бурятского государственного университета и Байкальского института природопользования СО РАН.

Эфирное масло получали методом гидродистилляции из воздушно-сухого сырья. Около 30 г сырья помещали в круглодонную колбу объемом 1000 мл, добавляли 500 мл воды и кипятили в течение 3 ч с момента закипания. Измерение проводили в трех повторностях. Полученное масло исследовали методом хромато-масс-спектрометрии на газовом хроматографе Agilent Packard HP 6890 N с квадрупольным массспектрометром (HP MSD 5973) в качестве детектора. Использовалась 30-метровая кварцевая колонка HP-5 MSD c внутренним диаметром 0,25 мм. Процентный состав эфирного масла вычисляли по площадям газохроматографических пиков без использования корректирующих коэффициентов. Качественный анализ основан на сравнении времен и индексов удерживания, а также полных масс-спектров, библиотеки хромато-массспектрометрических данных летучих веществ растительного происхождения. Вычисление линейных индексов удерживания $(J)$ выполняли в соответствии с [16]. Количественный анализ осуществляли методом внутренней нормировки по площадям пиков без использования корректирующих коэффициентов.

Таблица 1. Характеристика районов сбора исследованных образцов

\begin{tabular}{|c|c|c|}
\hline № & $\begin{array}{c}\text { Место сбора. Географические координаты, высота над уровнем моря. } \\
\text { Дата сбора }\end{array}$ & $\begin{array}{c}\text { Выход масла } \\
\text { (в \% от воздушно-сухого сырья) }\end{array}$ \\
\hline 1 & 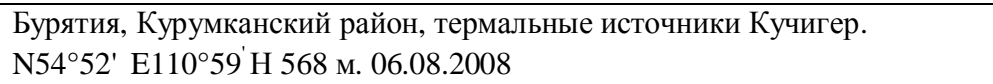 & $0,05 \pm 0,001$ \\
\hline 2 & $\begin{array}{l}\text { Бурятия, Баргузинский район, в } 5 \text { км от села Улюн к гольцам, } \\
\text { лесная поляна. N5350' E10951' Н } 609 \text { м. 05.08.2008 }\end{array}$ & $0,40 \pm 0,02$ \\
\hline 3 & $\begin{array}{l}\text { Бурятия, Иволгинский район, вдоль дороги. } \\
\text { N51³9' Е } 107^{\circ} 09^{\prime} \text { Н } 759 \text { м. 10.08.2008 }\end{array}$ & $0,06 \pm 0,001$ \\
\hline 4 & $\begin{array}{l}\text { Бурятия, Тункинский район, с. Аршан, остепненный луг. } \\
\text { N51 } 43^{\prime} \text { E102³4' Н } 716 \text { м. 29.07.2008 }\end{array}$ & $0,14 \pm 0,006$ \\
\hline 5 & $\begin{array}{l}\text { Бурятия, Селенгинский район, окр. с. Бараты, степь. } \\
\text { N } 51^{\circ} 15^{\prime} 00^{\prime \prime} \text { Е } 106^{\circ} 22^{\prime} 00^{\prime \prime} \text { Н } 576 \text { м. 10.08.2008. }\end{array}$ & $0,13 \pm 0,006$ \\
\hline 6 & $\begin{array}{l}\text { Монголия, Селенгинский аймак, местность Зуун -Мурен, степь. } \\
\text { N5006' E1054' Н } 635 \text { м.12.08.08 }\end{array}$ & $0,05 \pm 0,001$ \\
\hline 7 & $\begin{array}{l}\text { Бурятия, Иволгинский район, с. Сотниково, залежь. } \\
\text { N5152'60" E107²8'00" Н } 521 \text { м. 09.08.2010 }\end{array}$ & $0,10 \pm 0,005$ \\
\hline 8 & $\begin{array}{l}\text { Бурятия, Прибайкальский район, с. Турунтаево, залежь. } \\
\text { N52²10' E1074ㄴ ' Н } 548 \text { м.19.08.2010 }\end{array}$ & $0,29 \pm 0,01$ \\
\hline 9 & $\begin{array}{l}\text { Бурятия, Улан-Удэ, окр.ТЭЦ-1. } \\
\text { N 51²9'32" Е 107³7'34" Н } 502 \text { м. 12.08.2010 }\end{array}$ & $0,10 \pm 0,005$ \\
\hline 10 & $\begin{array}{l}\text { Бурятия, Улан-Удэ, ул. Лимонова, вдоль дороги. } \\
\text { N 5149'32" Е 107³7'34" Н } 502 \text { м. 12.08.2010 }\end{array}$ & $0,10 \pm 0,004$ \\
\hline 11 & $\begin{array}{l}\text { Бурятия, Кяхтинский район, Бурдунская степь. } \\
\text { N50²3' Е106³8' Н } 716 \text { м.18.08.2011 }\end{array}$ & $0,20 \pm 0,01$ \\
\hline 12 & $\begin{array}{l}\text { Бурятия, Иволгинский район, с. Сотниково, залежь. } \\
\text { N51 } 52^{\prime} 60^{\prime \prime} \text { Е107²8'00" Н } 521 \text { м. 23.08.2013 }\end{array}$ & $0,38 \pm 0,02$ \\
\hline
\end{tabular}

\section{Результаты и обсуждение}

Выходы эфирного масла из надземной части A. scoparia, произрастающих в различных районах Бурятии и в Селенгинском аймаке Монголии, варьируют в довольно широких пределах от 0,06 до $0,40 \%$. В образцах эфирного масла обнаружено свыше 100 соединений, большая часть из которых является из- 
вестными и легко идентифицируется. Компоненты эфирного масла представлены монотерпеновыми и сесквитерпеновыми соединениями, в некоторых образцах встречаются ациклические (нормальные алканы) и ароматические вещества (табл. 2). Монотерпеноиды составляют меньшую часть эфирного масла (2,9$57,7 \%)$. Наибольшее количество монотерпеновых соединений как по набору (ассортименту), так и по содержанию представлены в образце из Иволгинского района (№3, табл. 1, 2). В то время как в образце из Селенгинского района (окр. с. Бараты) отмечены только следовые количества с содержанием меньше $0,1 \%$. Основными монотерпеноидами является $n$-цимол $(0,6-15,2 \%)$, лимонен $(0,1-6,3 \%), \alpha$-пинен $(0,2-10,1 \%), \beta$ пинен $(0,4-8,9 \%)$, транс- $\beta$-оцимен $(0,3-5,4 \%)$. В эфирном масле из растений Курумканского района, произрастающих у термальных источников Кучигер, отмечено заметное содержание монотерпенового кетона - камфоры $(6,6 \%)$.

Доминирующими компонентами в эфирных маслах A. scoparia являются сесквитерпеновые соединения: кариофиллен (4,6-13,8\%), гермакрен D (11,5-40,3\%), спатуленол $(4,0-11,7 \%)$, оксид кариофиллена (4,3-15,6\%), кроме образцов из Иволгинского (2013 г. сбора) и Кяхтинского районов. Более половины эфирного масла из Кяхтинского района составляют гермакрен D (40,3\%) и кариофиллен $(13,8 \%)$. Образцы из Иволгинского района, собранные в 2008, 2010 гг., характеризуются заметным содержанием гермакрена D 11,5 и 26,2\% соответственно, тогда как в образце, собранном в 2013 г, он не обнаружен, но в значительном количестве найден $a r$-куркумен (14,3\%).

Анализ литературных данных показал, что состав эфирного масла из растений, произрастающих в различных странах, заметно различается. Так, основными компонентами эфирного масла из провинций Гилян, Мазандара, Кашан Ирана являются капиллен, камфора и 1-фенил-пента-2, 4-диен [5], из провинции Хорасан - $\alpha$-туйон $(55,4 \%), \beta$-туйон $(20,3 \%)$, камфора $(9,4 \%)$ и 1,8-цинеол $(5,9 \%)$ [6], провинции Тигран Ирана 3-пинен $(19,01 \%)$, капиллин $(17,45 \%)$, лимонен $(15,11 \%)$, мирцен $(10,96 \%)$, (z)-3-оцимен $(8,01 \%)$, (Е)-3-оцимен (7,33\%), $\alpha$-пинен (6,55\%), $\gamma$-терпинен (3,79\%) и 1,8-цинеол (3,56\%) [7]. Из листьев A. scoparia, культивироваемой в Индии, в качестве основных компонентов содержали $\gamma$-терпинен и эвгенол [8], $n$-цимол $(20,5 \%), \beta$-мирцен $(13,95 \%)$ и (+)-лимонен $(12,53 \%)$ [9]. В эфирных маслах из Южной Кореи 1,8 -цинеол и камфора [10], из Казахстана - метилэвгенол $(27,5 \%), n$-цимол $(19,8 \%)$, спатуленол $(8,76 \%)$ [11]. В более ранних работах показано, что надземная часть растений из Восточного Казахстана содержат агропирен, 1-фенилгексадиен-2,5, скопарол, линалоол, туйиловый спирт, геранилацетат, борнеол, терпиненол-4, $\alpha$-терпинеол, $\alpha$-туйол, $\beta$-туйен, $l$-камфора, $d$-карвол, $\alpha$-пинен, камфен, $\beta$-пинен, сабинен, $\alpha$-фелландрен, линалоол, $\beta$-фелландрен, $n$-цимол, лонгициклен, лонгифолен, сантолен, $\alpha$-химахилен, $\delta$-бизаболен, $\delta$-кадинен, $\alpha$-куркумен, тимол, эвгенол [12]. Эфирное масло полыни метельчатой, собранной в европейской части СНГ, различается по составу, в нем содержаться $\alpha$ - и $\beta$-пинены, мирцен, $a r$-куркумен, капиллен, капиллин, капиллол, $\beta$-кариофиллен-эпоксид, спатуленол, метилэвгенол, эвгенол и аромадендрен [13]. Основными компонентами эфирного масла A. scoparia флоры Таджикистана являются 1-фенил2,4 -пентадиен $(34,15 \%), \beta$-пинен $(21,3 \%)$, метилэвгенол $(5,49 \%), \alpha$-пинен $(5,38 \%)$, мирцен $(5,23 \%)$, лимонен $(5,02 \%)$, капиллен $(4,87 \%)$ и (Е)- $\beta$-оцимен $(3,83 \%)$ [14]. В эфирном масле из полыней, произрастающих на территории Монголии, в качестве основных компонентов отмечены транс- $\beta$-оцимен $(11,31-29,46 \%)$, $\alpha$-пинен $\quad(8,56-15,18 \%)$, мирцен $\quad(7,60-9,59 \%), \quad \gamma$-муролен $\quad(5,59-9,41 \%)$, зингиберен $\quad(2,26-3,29 \%)$, $\gamma$-куркумен (2,61-9,42\%), кариофиллен (1,6-6,06\%), спатуленол $(0,10-3,17 \%)$ [15]. Все составляющие эфирных масел A. scoparia могут быть объединены по структурным типам (группам) компонентов и путям их биогенеза. По составу основных компонентов эфирные масла A. scoparia можно разделить на следующие хемотипы: 1) содержащие ацетиленовые углеводороды - из провинций Гилян, Мазандара, Кашан, Тигран Ирана, Таджикистана, а также европейской части СНГ; 2) содержащие монотерпеновые и ароматические соединения - из провинции Хорасан Ирана, Индии, Южной Кореи; 3) содержащие монотерпеновые или ароматические и сесквитерпеновые соединения - Казахстан и Монголия.

Полученные нами результаты показывают, что компоненты A. scoparia флоры Бурятии представлены моно- и сесквитерпеновыми соединениями и соответствуют третьему хемотипу, характерному для полыни метельчатой из географически близких регионов. 
Таблица 2. Состав образцов эфирных масел Artemisia scoparia Waldst. Et Kit., произрастающих на территории Бурятии (образцы 1-5, 7-12) и Монголии (образец 6)*

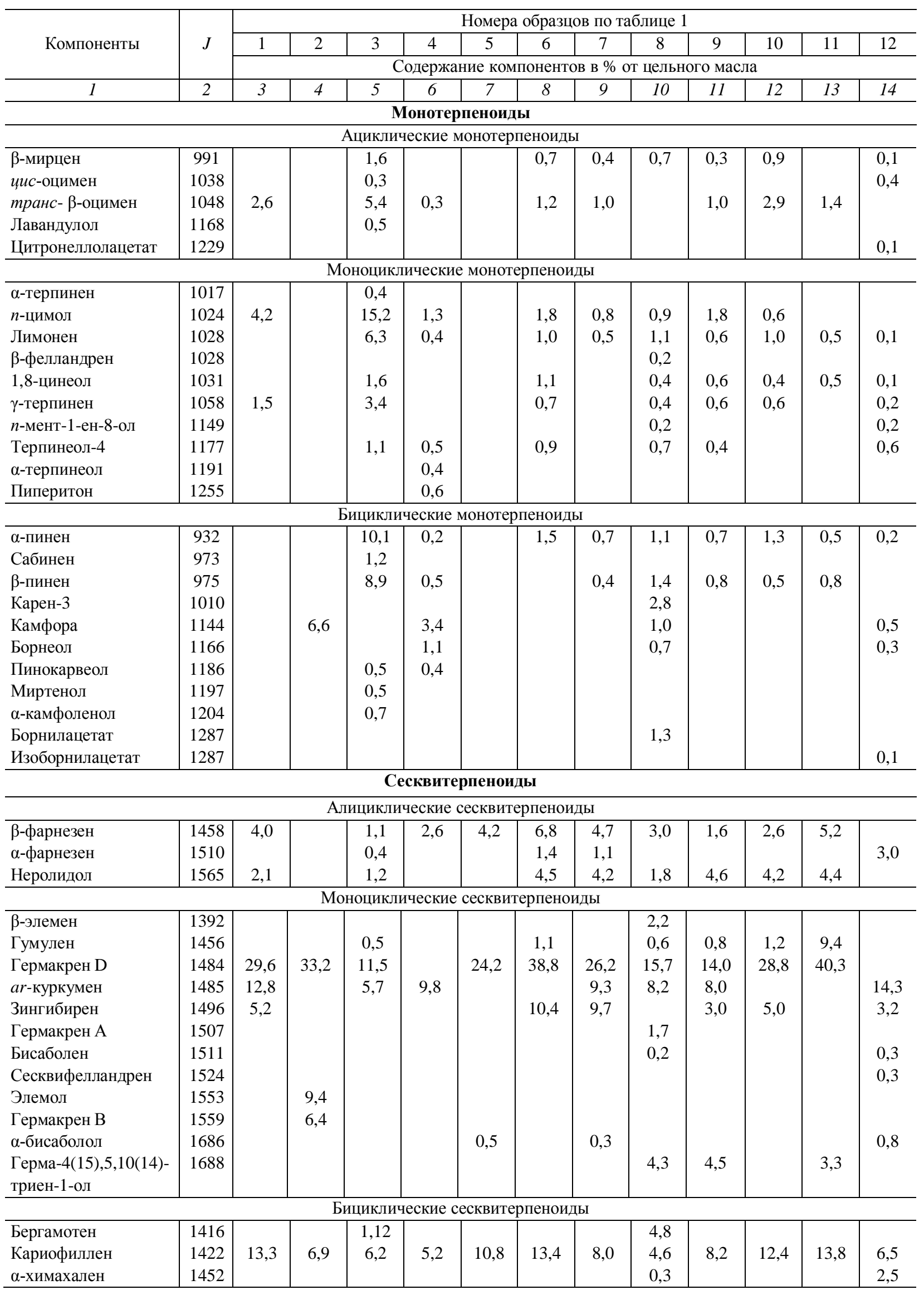


Окончание таблиць 2

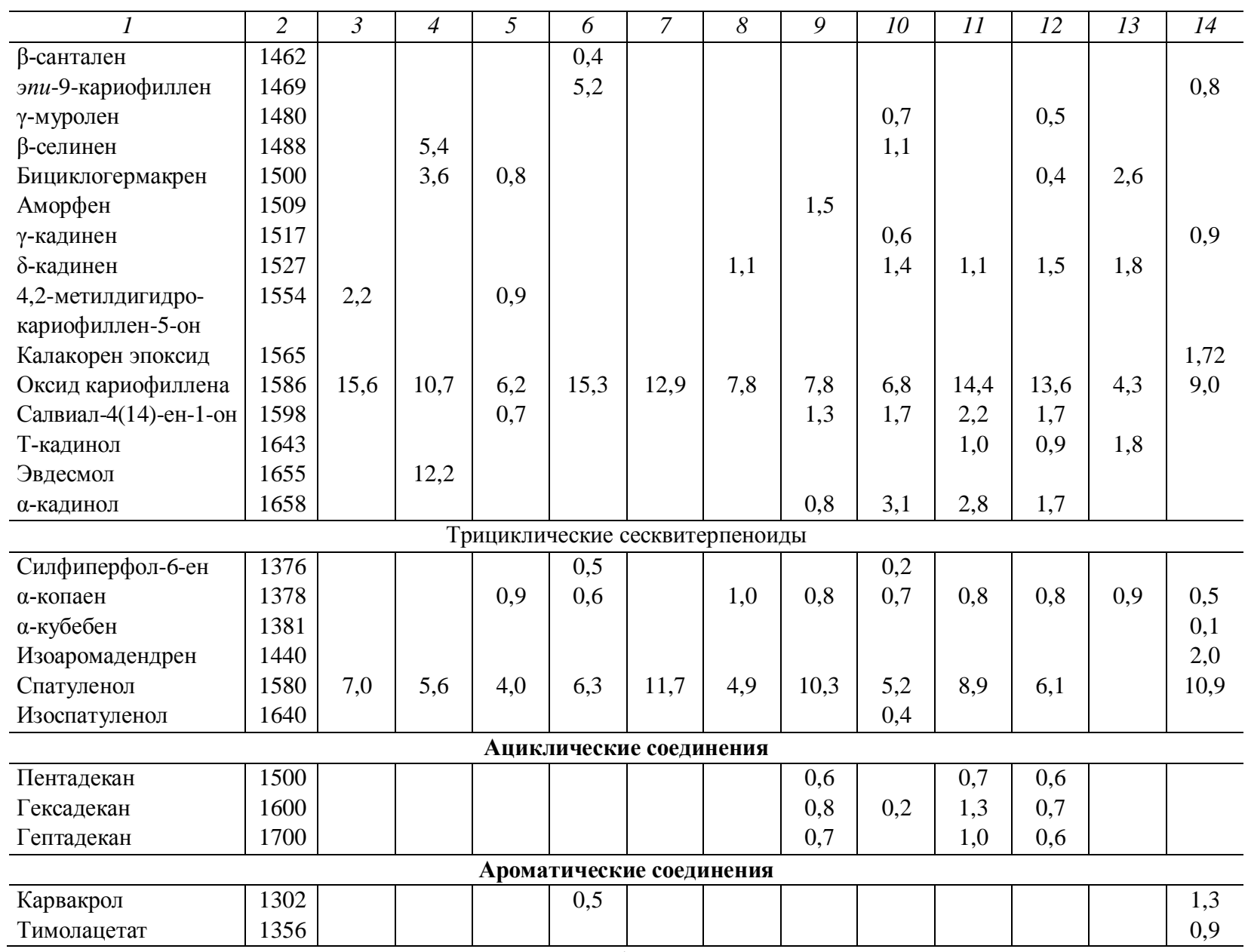

* В таблицу внесены компоненты, содержание которых в эфирном масле $\geq 0,1 \%$

\section{Заключение}

Анализ литературных и полученных нами данных по составу эфирного масла Artemisia scoparia Waldst. Et Kit. показал, что компонентный состав весьма вариабелен и во многом зависит от географической приуроченности. Основное сходство образцов эфирных масел растений полыни метельчатой, произрастающих на территории Бурятии и Монголии, заключается в наборе доминирующих компонентов, которые представлены монотерпеновыми ( $n$-цимол, лимонен, $\alpha$-пинен, $\beta$-пинен, транс- $\beta$-оцимен) и сесквитерпеновыми (кариофиллен, гермакрен D, спатуленол, оксид кариофиллена) соединениями. По групповому составу доминирующих компонентов эфирных масел полыни метельчатой флоры Бурятии близки к растениям из Монголии и Казахстана.

\section{Список литературы}

1. Шатар С., Бодоев Н.В., Жигжитжапова С.В., Алтанцэцэг Ш., Намзалов Б.Б. Эфироносные растения бассейна реки Селенга. Улан-Удэ, 2006. 133 с.

2. Аненхонов О.А., Пыхалова Т.Д., Осипов К.И., Сэкулич И.Р., Бадмаева Н.К., Намзалов Б.Б., Кривобоков Л.В., Мункуева М.С., Суткин А.В., Тубшинова Д.Б., Тубанова Д.Я. Определитель растений Бурятии. Улан-Удэ, $2001.672 \mathrm{c}$.

3. Телятьев В.В. Целебные клады. Иркутск, 1991. 400 с.

4. Shanta Mehrotra, A.K.S. Rawat, Usha Shome Antimicrobial activity of essential oils of some indian Artemisia species // Fitoterapia. 1993. Vol. LXIV, N1. Pp. 65-68.

5. Safaei-Ghomi J., Bamoniri A., Sarafraz M.B., Batooli H. Volatile components from Artemisia scoparia Waldst. et Kit. growing in central Iran //Flav. Fragr. J. 2005. Vol. 20. Pp. 650-652.

6. Mirjalili M.H., Nejad Ebrahimi S., Sonboli A., Tabatabaei S.M.F., Hadian J. Phenological Variation of the Essential Oil of Artemisia scoparia Waldst. et Kit from Iran // J. Essent. Oil Res. 2007. Vol. 19. Pp. 326-329. 
7. Negahban M., Moharramipour S., Sefidkon F. Chemical Composition and Insecticidal Activity of Artemisia scoparia Essential Oil against Three Coleopteran Stored-Product Insects // J. Asia-Pacific Entomol. 2006. Vol. 9(4). Pp. 381-388.

8. Ali M., Chaudhary A., Ramachandram R. Volatile oil constituents of Artemisia scoparia leaves // J. Med. Arom. Plant. Sci. 2000. Vol. 22. Pp. 366-369.

9. Kaur Sh., Singhb H., Mittal S., Batish D. R., Kohli R. K. Phytotoxic effects of volatile oil from Artemisia scoparia against weeds and its possible use as a bioherbicide // Industrial Crops and Products. 2010. Vol. 32. Pp. 54-61.

10. Cha J.D., Jeong M.R., Jeong S.I., Moon S.E., Kim J.Y., Kil B.S., Song Y.H. Chemical composition and antimicrobial activity of the essential oil of Artemisia scoparia and A. capillaries // Planta Med. 2005. Vol. 71. Pp. 186-190.

11. Basher K. H. C., Ozek T., Demirehakmak B., Nuriddinov Kh. R., Abduganiev B. Yo., Aripov Kh. N. et al. Essential oils of some Artemisia species from central Asia // Chemistry of Natural Compounds. 1997. Vol. 33. Pp. $293-295$.

12. Горяев М.И., Шарипова Ф.С., Ельчибекова Л.А., Аверина В.Ю. Эфирное масло Artemisia scoparia // Химия природных соединений. 1981. №5. С. 560-564.

13. Коновалов Д.А., Коновалова О.А., Челомбитько В.А. О химическом составе эфирного масла Artemisia scoparia // Химия природных соединений. 1992. №1. С. 142-143.

14. Шаропов Ф.С., Сулаймонова В.А., Гулмуродов И.С., Холмадов М.Н. Состав эфирного масла полыни метельчатой (Artemisia scoparia Waldst. et Kit.), произрастающей в Таджикистане // Доклады академии наук Республики Таджикистан. 2011. Т. 54, №10. С. 841-844.

15. Шатар С., Алтанцэцэг Ш. Монгол нутгийн шарилжны эфирийн тосны химийн бурэлдэхееун, технологи чанар ач холбогдол. Улаанбаатор хот, 2011. 225 с.

16. Ткачев А.В. Исследование летучих веществ растений. Новосибирск, 2008. 969 с.

Поступило в редакциию 4 сентября 2014 г.

После переработки 22 сентября 2014 г. 
Zhigzhitzhapova S.V. ${ }^{1,2}$, Randalova T.E. ${ }^{2 *}$, Radnaeva L.D. ${ }^{1,2}$ COMPOSITION OF ESSENTIAL OIL OF ARTEMISIA SCOPARIA WALDST. ET KIT., GROWING IN BURYATIA AND MONGOLIA

${ }^{1}$ Buryat State University, Smolin Str. 24a, Ulan-Ude, 670000 (Russia),e-mail: soktoevate@ gmail.com

${ }^{2}$ Baikal Institute of Nature Management Siberian Branch of RAS, Sakh'yanovoy Str., 8, Ulan-Ude, 670047 (Russia)

Essential oil isolated from the Artemisia scoparia Waldst.et Kit. by hydrodistillation method. Samples for analysis we collected in different areas of the Republic of Buryatia and Mongolia. The content of the essential to vary quite widely from 0,06 to $0,40 \%$ from aerial parts of A. scoparia, growing in various districts of Buryatia and in Selenginsky aimak of Mongolia. Component composition analyzed by gas-chromatography-mass-spectrometry of the oil. In total, there were found more than 100 compounds. The main components of essential oil were identified: $p$-cymol $(0,6-15,2 \%)$, limonene $(0,1-6,3 \%), \alpha-$ pinene $(0,2-10,1 \%), \beta$-pinene $(0,4-8,9 \%)$, germacrene D $(11,5-40,3 \%)$, trans- $\beta$-ocimene $(0,3-5,4 \%)$, caryophyllene $(4,6-13,8 \%)$, spatchulenol $(4,0-11,7 \%)$, caryophyllene oxide $(4,3-15,6 \%)$. The composition of the main substances of essential oils of $A$. scoparia can be divided into the following chemotypes: 1) containing acetylenic hydrocarbons - from the provinces of Gilan, Mazandara, Kashan, Tigran Iran, Tajikistan, as well as the European part of the CIS; 2) containing monoterpene and aromatic compounds - from the province of Khorasan, Iran, India, South Korea 3) containing monoterpene and sesquiterpene and aromatic compounds - Kazakhstan and Mongolia. The main components of the essential oil of A. scoparia presented mono-and sesquiterpene compounds for Buryatian flora. This is the third chemotype of $A$. scoparia from geographically close regions.

Keywords: essential oil, Artemisia scoparia Waldst.et Kit., gas-chromatography-mass-spectrometry

\section{References}

1. Shatar S., Bodoev N.V., Zhigzhitzhapova S.V., Altantsetseg Sh., Namzalov B.B. Efironosnye rasteniia basseina reki Selenga. [Efironosnye plants Selenga River Basin]. Ulan-Ude, 2006, 133 p. (in Russ.).

2. Anenkhonov O.A., Pykhalova T.D., Osipov K.I., Sekulich I.R., Badmaeva N.K., Namzalov B.B., Krivobokov L.V., Munkueva M.S., Sutkin A.V., Tubshinova D.B., Tubanova D.Ia. Opredelitel' rastenii Buriatii. [Guide to the Plants of Buryatia]. Ulan-Ude, 2001, 672 p. (in Russ.).

3. Teliat'ev V.V. Tselebnye klady. [Healing treasures]. Irkutsk, 1991, 400 p. (in Russ.).

4. Shanta Mehrotra, A.K.S. Rawat, Usha Shome. Fitoterapia, 1993, vol. LXIV, no. 1, pp. 65-68.

5. Safaei-Ghomi J., Bamoniri A., Sarafraz M.B., Batooli H. Flav. Fragr. J., 2005, vol. 20, pp. 650-652.

6. Mirjalili M.H., Nejad Ebrahimi S., Sonboli A., Tabatabaei S.M.F., Hadian J. J. Essent. Oil Res., 2007, vol. 19, pp. 326-329.

7. Negahban M., Moharramipour S., Sefidkon F. J. Asia-Pacific Entomol., 2006, vol. 9(4), pp. 381-388.

8. Ali M., Chaudhary A., Ramachandram R. J. Med. Arom. Plant. Sci., 2000, vol. 22, pp. 366-369.

9. Kaur Sh., Singhb H., Mittal S., Batish D.R., Kohli R.K. Industrial Crops and Products, 2010, vol. 32, pp. 54-61.

10. Cha J.D., Jeong M.R., Jeong S.I., Moon S.E., Kim J.Y., Kil B.S., Song Y.H. Planta Med., 2005, vol. 71, pp. $186-190$.

11. Basher K. H. C., Ozek T., Demirehakmak B., Nuriddinov Kh. R., Abduganiev B. Yo., Aripov Kh. N. et al. Chemistry of Natural Compounds, 1997, vol. 33, pp. 293-295.

12. Goriaev M.I., Sharipova F.S., El'chibekova L.A., Averina V.Iu. Khimiia prirodnykh soedinenii, 1981, no. 5, pp. 560-564. (in Russ.).

13. Konovalov D.A., Konovalova O.A., Chelombit'ko V.A. Khimiia prirodnykh soedinenii, 1992, no. 1, pp. 142-143. (in Russ.).

14. Sharopov F.S., Sulaimonova V.A., Gulmurodov I.S., Kholmadov M.N. Doklady akademii nauk Respubliki Tadzhikistan, 2011, vol. 54, no. 10, pp. 841-844. (in Russ.).

15. Shatar S., Altantsetseg S. Mongol nutgiyn sharilzhny efiriyn Tosna himiyn byreldeheeyn technologists chanar ach holbogdol. Ulaanbaator hot, 2011, 225 p. (in Mongolian).

16. Tkachev A.V. The study of plant volatiles. [The study of plant volatiles]. Novosibirsk, 2008, 969 p. (in Russ.).

Received September 4, 2014

Revised September 22, 2014

\footnotetext{
* Corresponding author.
} 
